When reviewing all 2WW referrals for gastroscopy the cancers pick up was $10 \%$ with the majority of examinations being normal or identifying insignificant findings.

Conclusion The two week wait referral system is often considered to be a poor method for detecting oesophagogastric cancer. In our data $10 \%$ patients referred in this manner had oesophagogastric cancer which is consistant with existing data. However when looking at all cases of of cancer diagnosed in this time period the 2WW represents the pathway for diagnosis for over half our malignancies (56\%). Our cohort of patients showed similar TNM staging at the time of diagnosis irrespective whether they were refered routinely or on an urgent basis.

This suggests that the $2 \mathrm{ww}$ is an important pathway for referral of upper gastrointestinal malignancies but unfortunately does not identify patients at earlier stage. This is probably due to the lack of symptoms in early oesophogogastric cancer and strengthens the argument for identifying patients at an earlier stage perhaps by screening or surveillance of high risk groups.

Disclosure of Interest None Declared

\section{PTU-170 OESOPHAGEAL PERFORATION RESULTING FROM BAND ACHALASIA - A DELAYED COMPLICATION OF LAPAROSCOPIC ADJUSTABLE GASTRIC BANDING}

doi:10.1136/gutjnl-2013-304907.260

1,"S Shaikh, ${ }^{2} \mathrm{~S}$ Dexter, ${ }^{1} \mathrm{~J}$ Jameel. ${ }^{1}$ Surgery, Dewsbury District Hospital, Dewsbury; ${ }^{2}$ Surgery, St James University Hospital, Leeds, UK

Introduction Laparoscopic adjustable gastric banding (LAGB) is a common bariatric procedure in the UK due to its relative technical ease and reversibility. The technique has been around since the 1990s and although its immediate complications have been evident and known, the longer term complications are still emerging and not yet completely understood. Oesophageal dysmotility postLAGB is now increasingly being recognised as a long-term complication associated with LAGB. This paper presents a potentially life-threatening complication associated with oesophageal dysmotility more than a decade after LAGB placement.

Methods A 58yr old lady presented with chronic cough and mediastinal widening on chest X-ray. A computed tomogram (CT) revealed a mega-oesophagus with a collection in the mediastinum in keeping with a contained oesophageal perforation and a LAGB in situ. On further questioning, she mentioned that she had had a LAGB placed 12yrs previously.. She had been experiencing recurrent coughs, chest infections, weight loss and dysphagia for 2 yrs but had not sought medical help.

Results The LAGB was completely emptied ( $9 \mathrm{mls}$ of fluid). She was managed conservatively with nil orally, nasogastric drainage, antibiotics, parenteral nutrition over a period of 4 weeks and serial imaging was performed to monitor progress. She responded well to it, the perforation had completely healed, she resumed oral intake and was discharged.

Conclusion While oesophageal dysmotility is emerging as a long-term complication occurring around 5-7 yrs post-LAGB, its association with oesophageal perforation has not been described in the literature prior to this incident. It is likely that oesophageal dysmotility resulted in mega-oesophagus and the associated reflux caused frequent coughing in our patient. The valsalva manoeuvre during coughing which closes the cricipharyngeus proximally and the presence of LAGB distally may have generated a high pressure zone within the oesophagus leading to perforation. This was a potentially life-threatening complication. This re-inforces the importance of life-long commitment to follow-up in patients who undergo bariatric surgery. We suggest at-risk patients developing mega-oesophagus should be identified and timely band-emptying performed to avoid this serious complication. Further long-term cohort studies need to be performed to determine the exact prevalence of oesophageal dysmotility and such complications.

Disclosure of Interest None Declared.

\section{PTU-171 BURIED BARRETT'S DYSPLASIA ('BBAD') STUDY: RESULTS FROM A LONG TERM FOLLOW UP STUDY OF BARRETT'S NEOPLASIA COHORT}

doi:10.1136/gutjnl-2013-304907.261

1.*S Tholoor, 'R Bhattacharyya, '10 Tsagkournis, 'P Basford, 'P Bhandari. 'Portsmouth Hospitals NHS Trust, Portsmouth, UK

Introduction Buried Barrett's' or Subsquamous intestinal metaplasia (SSIM) refers to glands which are 'buried' underneath the squamous epithelium. High dose acid suppressive therapy and lack of acid exposure can result in squamous re-epithelialisation over the Barrett's mucosa. Buried Barrett's can pose significant diagnostic and surveillence challenges. Data on the prevalance of Buried Barrett's in endoscopic therapy naïve patients is limited. Like wise there is limted data on the prevalance of Buried Barrett's in patients following EMR. We aim to study and compare the prevalence of Buried Barrett's in these two groups of patients.

Methods

Inclusion Criteria:

- Patients with Barrett's referred for endoscopic treatment between June 06 and June 12

- Patients with Barrett's dysplasia following EMR procedure. Biopsy:

- Biopsies were first obtained from any suspicious looking area. Following this, biopsies were then obtained from the neosquamous area. Finally, random biopsies were obtained. These were sent in separate cassettes. Histopathology was reported by two independent GI pathologists and was prospectively recorded on a central pathology database.

- Buried Barrett's was defined as any metaplastic or glandular tissue beneath the squamous epithelium. Pathology specimens were reported by 2 independent, accredited GI pathologists.

\section{Results}

Abstract PTU-171 Table 1 Buried Barrett's with and without dysplasia

\begin{tabular}{lll}
\hline & $\begin{array}{l}\text { Buried Barrett's in } \\
\text { endoscopic therapy naïve } \\
\text { patients }\end{array}$ & $\begin{array}{l}\text { Buried Barrett's in patients } \\
\text { post EMR procedure }\end{array}$ \\
\hline Total & $16 / 83(19 \%)$ & $22 / 83(26.5 \%)$ \\
Buried Barrett's with no & $2 / 83(2.4 \%)$ & $9 / 83(10.8 \%)$ \\
dysplasia & $14 / 83(16.8 \%)$ & $13 / 83(15.6 \%)$ \\
Buried Barrett's dysplasia & $9 / 83(10.8 \%)$ & $4 / 83(4.8 \%)$ \\
HGD & $3 / 83(3.6 \%)$ & $4 / 83(4.8 \%)$ \\
IMC & $12 / 83(14.5 \%)$ & $8 / 83(9.6 \%)$ \\
HGD + IMC & $2 / 83(1.2 \%)$ & $5 / 83(6 \%)$ \\
LGD & & \\
\hline
\end{tabular}

\section{Conclusion}

Our study shows that in the pre-EMR cohort, there was an overall prevalence of $15.7 \%$ of buried Barrett's and a $14.5 \%$ prevalence of buried Barrett's with high grade neoplasia (HGD or IMC).

Our results in the post EMR cohort shows an overall prevalence of $33.7 \%$ of buried Barrett's with $9.6 \%$ prevalence of buried high grade neoplasia (HGD or IMC) suggesting that a third of patients undergoing EMR for Barrett's dysplasia harbour buried Barrett's and a third of these patients harbour high grade neoplasia. This has significant implications for post EMR endoscopic assessment and surveillance.

The results from our study shows that there is a need to develop and maintain proficiency in sampling techniques in patients with Barrett's oesophagus. It also shows that the biopsies particularly from those with dysplasia should be carefully reviewed by 